\title{
Resection of liver metastases is beneficial in patients with gastric cancer: report on 15 cases and review of literature
}

\author{
Yves Dittmar • Annelore Altendorf-Hofmann • \\ Falk Rauchfuss • Max Götz $\cdot$ Hubert Scheuerlein • \\ Karin Jandt • Utz Settmacher
}

Received: 7 March 2011/ Accepted: 19 July 2011/Published online: 3 September 2011

(c) The International Gastric Cancer Association and The Japanese Gastric Cancer Association 2011

\begin{abstract}
Background Although up to $9 \%$ of patients with gastric cancer develop liver metastases, liver resection is rarely performed because of co-existing non-curative factors. Furthermore, the benefit of liver resection is still controversially discussed. Our goal was to investigate the outcome of patients who underwent liver resection or radiofrequency ablation (RFA) for hepatic metastasized gastric cancer.

Methods Retrospectively collected data from a prospectively maintained database were analyzed from 15 patients who underwent liver resection or RFA for liver metastases from gastric cancer.

Results Overall 5-year survival and median survival were $27 \%$ and 48 months for resected/RFA patients. The perioperative complication rate was low. One patient has been tumor-free for 90 months now.

Conclusions Liver resection in patients with hepatic metastasized gastric cancer is beneficial and safe if an R0 situation can be achieved. RFA might be a useful alternative in those patients where surgery is not feasible.
\end{abstract}

Keywords Gastric cancer - Liver metastases - Liver resection $\cdot$ Survival $\cdot$ Radiofrequency ablation

\section{Introduction}

Gastric cancer is known to be the second most frequent cause of cancer-related death [1]. Due to its late onset and

Y. Dittmar $(\varangle) \cdot$ A. Altendorf-Hofmann · F. Rauchfuss ·

M. Götz $\cdot$ H. Scheuerlein · K. Jandt - U. Settmacher

Department of General, Visceral and Vascular Surgery, University of Jena, Erlanger Allee 101, 07740 Jena, Germany

e-mail: yves.dittmar@med.uni-jena.de unspecific symptoms, the majority of patients with gastric cancer initially present with an advanced tumor stage [2].

Only a minority of patients can be cured when there is advanced local tumor spread or when other organs are infiltrated by distant metastases. Liver metastases develop in 5-9\% of patients with gastric cancer [3].

Several publications have addressed the issue of surgery for hepatic metastasized gastric cancer in Asia [4-8]. Only a few reports have been published by western authors [3, 9]. There is increasing evidence in the literature that hepatectomy for metastases from gastric cancer can improve survival when an R0 resection can be achieved.

Our goal was to assess the clinical outcome of patients with hepatic metastasized gastric carcinoma who underwent aggressive treatment in comparison to those patients who received non-surgical/non-interventional treatment. Furthermore, we aimed to investigate whether liver resection is a safe procedure with an acceptable peri-operative complication rate in these patients. Therefore, we performed a retrospective analysis based on prospectively collected data from the clinical cancer registry. We report our experiences with 15 patients with hepatic metastasized gastric carcinoma that was treated surgically in our hospital.

\section{Patients and methods}

Patient acquisition

From 1995 to 2009, 713 patients with gastric cancer were treated in our hospital. Only cases of adenocarcinoma were considered for this study.

Among these 713 patients, a total of 142 patients (19.9\%) developed liver metastases; 98 of these 142 patients presented with isolated liver metastases either 
synchronously or metachronously after R0 resection of the primary tumor. Eventually, 15 patients with liver metastases underwent liver resection or interventional eradication of liver tumors by radiofrequency ablation. We performed liver resection only in cases where potentially curative resections were a realistic possibility; 83 of the 98 patients with isolated liver metastases were not considered for aggressive treatment of the liver metastases. In 79 of these patients liver tumors were not resectable due to tumor growth in multiple liver segments; the remaining 4 patients were not eligible for surgery due to severe cardiopulmonary dysfunction.

\section{Clinical and histopathological data}

We analyzed, retrospectively, data from a prospectively maintained tumor register database for the above 15 patients who underwent liver resection or interventional eradication of liver tumors by radiofrequency ablation with respect to clinical characteristics (gender, patient age, other non-gastric malignancies), tumor-specific data (detailed staging of the primary tumor, number and location of liver tumors, histopathological characteristics), peri-operative data (morbidity, mortality, duration of hospital stay), and follow-up-data (duration of follow-up, overall survival, incidence of recurrence).

Clinical data about chemotherapy were available for all patients who underwent liver surgery and such data were also available for 80 patients who did not undergo liver surgery and who had isolated tumors only within the liver (3 cases missing).

\section{Definitions}

Metastases were defined as synchronous when liver tumors were detected simultaneously with the primary tumor or within the first three months thereafter. All other liver tumors were regarded as metachronous metastases. Complications were classified according to the Clavien scheme [10].

Radiofrequency ablation was performed in liver tumors that were smaller than $5 \mathrm{~cm}$ in diameter, and the completeness of tumor eradication was confirmed by computed tomography with contrast agent by using a General Electrics device (64 slices). The tumor was regarded as being completely eradicated when there was no contrast agent uptake within the tumor lesion and when the tumor lesion was regredient according to the Response Evaluation Criteria in Solid Tumors (RECIST).

Statistical analysis

Statistical analysis was performed with SPSS version 19.0 (SPSS, Chicago, IL, USA). For univariate analysis, binomial and categorical data were evaluated by crosslinked tables and the exact Fisher test. Results were regarded as being statistically significant when the $P$ value was lower than 0.05 . For survival analysis, the KaplanMeier method was used. For comparisons of subgroups, statistical significance was measured by the log rank test.

A literature search was performed in the PubMed database using the following key words: gastric cancer, liver metastases, liver resection, radiofrequency ablation, hepatectomy, survival, recurrence.

\section{Results}

Demographic and histopathological data

The study group consisted of 12 male and 3 female patients. The median age of the study group was 57 years (range 25-82 years). Eleven patients had a lymph nodepositive stage of the primary tumor, and 4 patients did not have lymph node involvement. While 9 patients presented initially with hepatic metastasized gastric cancer, 6 patients had metachronous liver metastases. The median interval from diagnosis of the primary tumor until diagnosis of the liver metastases was 11.8 months (range 7-26 months).

Demographic and tumor-related data are summarized in Table 1.

The median size of the largest liver tumor was $26 \mathrm{~mm}$ (range 20-80 mm). The median distance between the liver tumor and the resection margin was $6 \mathrm{~mm}$ (range $1-45 \mathrm{~mm})$.

\section{Surgical procedure}

Fifteen of 98 patients with isolated liver metastases underwent hepatectomy or radiofrequency ablation; this corresponds to a resection/intervention rate of $15 \%$. Among the 10 patients who underwent liver resection, the most frequent procedure was anatomic resection of one or two liver segments. The detailed procedures are listed in Table 2.

The incidence of complications in the peri-operative course was acceptable: impaired wound healing occurred in two patients (13\%, surgical therapy in one patient: $7 \%$ ), blood transfusion was given in three patients $(20 \%)$, and a pleural effusion was observed in 4 patients $(27 \%)$. There was no peri-operative mortality.

Eighty-three patients were not considered for aggressive treatment of the liver metastases. Of these, 65 patients presented with synchronous liver metastases and 18 presented with metachronous liver metastases. In most cases $(n=79)$ the reason for the decision against aggressive treatment was the presence of a technically unresectable 
Table 1 Demographic, clinical, and histopathological data of patients who underwent liver resection or radiofrequency ablation

\begin{tabular}{|c|c|}
\hline \multicolumn{2}{|l|}{ Gender } \\
\hline Male & 12 \\
\hline Female & 3 \\
\hline \multicolumn{2}{|l|}{ Grading of the primary tumor } \\
\hline Well or moderately differentiated & 4 \\
\hline Poorly differentiated or undifferentiated & 11 \\
\hline \multicolumn{2}{|l|}{$\mathrm{T}$ stage of the primary tumor } \\
\hline $\mathrm{T} 2$ & 8 \\
\hline $\mathrm{T} 3$ & 5 \\
\hline $\mathrm{T} 4$ & 2 \\
\hline \multicolumn{2}{|l|}{$\mathrm{N}$ stage of the primary tumor } \\
\hline No & 4 \\
\hline N1 & 6 \\
\hline $\mathrm{N} 2$ & 4 \\
\hline N3 & 1 \\
\hline $\begin{array}{l}\text { Lymph node quotient of the primary tumor } \\
\text { (median, confidence interval) }\end{array}$ & $\begin{array}{l}0.240 \\
\quad(0.0825-0.3651)\end{array}$ \\
\hline \multicolumn{2}{|l|}{ Lymphangiosis of the primary tumor } \\
\hline Yes & 6 \\
\hline No & 15 \\
\hline \multicolumn{2}{|l|}{ Venangiosis of the primary tumor } \\
\hline Yes & 1 \\
\hline No & 14 \\
\hline \multicolumn{2}{|l|}{ Perineural sheath invasion from the primary tumor } \\
\hline Yes & 2 \\
\hline No & 13 \\
\hline \multicolumn{2}{|l|}{ Classification according to Lauren } \\
\hline Diffuse & 5 \\
\hline Intestinal & 10 \\
\hline \multicolumn{2}{|l|}{ Chronology of metastases } \\
\hline Synchronous & 9 \\
\hline Metachronous & 6 \\
\hline \multicolumn{2}{|l|}{ Number of liver tumors } \\
\hline Solitary & 8 \\
\hline 2 or more & 7 \\
\hline \multicolumn{2}{|l|}{ Distribution of liver tumors } \\
\hline Unilobar & 12 \\
\hline Bilobar & 3 \\
\hline $\begin{array}{l}\text { Diameter of the largest liver tumor (median, } \\
\text { confidence interval) }\end{array}$ & $\begin{array}{l}26 \mathrm{~mm} \\
(22-46 \mathrm{~mm})\end{array}$ \\
\hline
\end{tabular}

tumor spread within the liver (bilobar and diffuse distribution in multiple liver segments); in the remaining 4 patients the cardiopulmonary performance was poor.

Overall survival and incidence of tumor recurrence

In the whole group of 713 patients, the median follow-up period was 11 months (range $0-159$ ) for the 514 patients
Table 2 Radiofrequency ablation and surgical procedures in patients with gastric liver metastases

\begin{tabular}{ll}
\hline Procedure & Number of patients \\
\hline Radiofrequency ablation & 5 \\
Liver resection & \\
Minor resection & \\
$\quad$ Atypical resection & 1 \\
1 liver segment & 2 \\
2 liver segments & 5 \\
Major resection (hemihepatectomy) & 2 \\
\hline
\end{tabular}

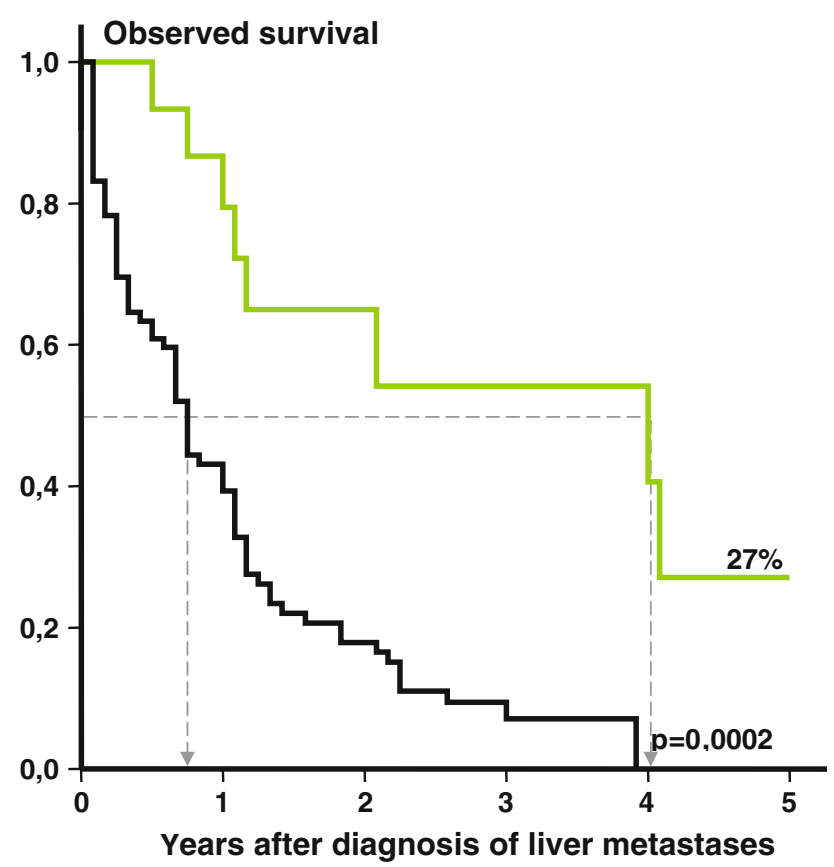

Fig. 1 Overall survival of patients with hepatic metastases from gastric cancer (green line liver resection or radiofrequency ablation, black line patients who did not receive resection or thermoablation, $\log \operatorname{rank} P=0.0002$ )

who died, and the period was 44 (range $0-159$ ) months for those 199 patients who are still alive. The median survival of the 15 patients who underwent resection and/or eradication of liver metastases was 48 months (overall 5-year survival 27\%, see Fig. 1), whereas for the 83 patients who did not undergo surgical treatment or radiofrequency ablation the median survival was 9 months (overall 5-year survival $0 \%, P=0.0002$ ).

One patient has been tumor-free for 74 months now.

The patient's gender and age; T-stage; tumor differentiation; allocation according to Laurèn's classification; presence or absence of lymphangiosis, venangiosis, and infiltration of the perineural sheath; and lymph node involvement (number of positive lymph nodes, lymph node quotient, $\mathrm{N}$ stage) had no influence on overall survival or 
on the incidence of recurrence. Furthermore, there was no difference between synchronous and metachronous metastases in our study group in terms of survival.

\section{Discussion}

Whereas liver metastases develop in approximately $50 \%$ of all patients with colorectal carcinoma, the incidence of liver metastases from primary gastric cancer ranges from 5 to $9 \%$.

Liver resection for secondary tumor growth is performed mainly in patients with colorectal liver metastases, with resection rates of between 20 and $30 \%$ and a 5-year survival rate of $25-58 \%$ [11, 12]. In contrast, liver resection for hepatic metastasized gastric carcinoma is a rarely performed procedure: resection rates of liver metastases from gastric cancer range from 11 to $21 \%$ [5, 6]. Our resection rate $(16 \%)$ was within that range.

The majority of patients with hepatic metastasized gastric carcinoma remain incurable due to several frequently occurring factors, even if extended or multivisceral surgery has been performed [3,13]. These incurable factors include bilobar multinodular tumor spread, gross peritoneal dissemination, diffuse metastases of distant lymph nodes, or unresectable local recurrence $[4,14]$. Especially, bilobar tumor spread within the liver is more frequent in gastric cancer as compared to other gastrointestinal malignancies, in spite of the same venous drainage via the portal vein; this raises the questions of whether the pathway of liver metastases from gastric cancer follows the portal venous flow or whether these metastases are, rather, caused by free circulating tumor cells and thus have to be regarded as a generalized stage of the disease. This distinct biological behavior may also reflect that the molecular signaling and gene expression pattern is different from the patterns in other gastrointestinal tumors. Even in cases of potentially resectable gastric liver metastases, many medical professionals are reluctant to consider these patients for radical surgical treatment.

In the last decade of the twentieth century, several case reports of liver resection for gastric liver metastases were published. In addition, some small patient cohorts were included in retrospective studies that were dedicated to the liver resection of non-colorectal metastases and later, the liver resection of non-colorectal-non-neuroendocrine metastases [15-17]. The first publication dedicated to the clinical outcome after liver resection for gastric cancer metastases was presented by Ochiai et al. [6]: they described serosal perforation by the primary tumor (in cases of synchronous liver metastases) as well as lymphangiosis and venangiosis to be negative prognostic factors, and reported a median survival time of 18 months and an overall 5-year survival rate of $19 \%$. One of the first western publications with a focus on the resection of gastric liver metastases was presented in 2002 by Zacherl et al. [9]: the median survival of the 15 resected patients was 8.8 months, while two of these patients survived for more than 3 years. In a recently published review, 19 studies were analyzed to compare the survival following liver resection for hepatic metastasized gastric cancer. The median survival for all 436 patients was 17 months, and the 5 -year survival was $26.5 \%$. No prognostic factor was found to be statistically significant across all studies [18]. Table 3 shows further studies on the topic of radical surgery for gastric liver metastases that have been published since 1994. At present, there are no data available on results from a prospectively conducted trial.

In our study group, we found a median survival of 48 months and an overall 5-year-survival-rate of $27 \%$ for those patients who underwent resection or radiofrequency ablation for liver metastases. The poorer survival in the
Table 3 Review of the literature regarding liver resection for hepatic metastasized gastric cancer

\begin{tabular}{lllll}
\hline Author & $\begin{array}{l}\text { Year of } \\
\text { publication }\end{array}$ & $\begin{array}{l}\text { Number of } \\
\text { cases }(n)\end{array}$ & $\begin{array}{l}\text { Median survival } \\
\text { in months }\end{array}$ & $\begin{array}{l}\text { Overall 5-year } \\
\text { survival (\%) }\end{array}$ \\
\hline Ochiai et al. [6] & 1994 & 21 & 18 & 19 \\
Miyazaki et al. [7] & 1997 & 21 & NA & 9.5 \\
Fujii et al. [8] & 2001 & 10 & 16.3 & 10 \\
Imamura et al. [22] & 2001 & 17 & 12 & 0 \\
Ambiru et al. [23] & 2001 & 40 & 12 & 18 \\
Zacherl et al. [9] & 2002 & 15 & 8.8 & NA \\
Saiura et al. [24] & 2002 & 10 & 25 & 20 \\
Okano et al. [5] & 2002 & 19 & 21 & 34 \\
Shirabe et al. [25] & 2003 & 36 & NA & 36 \\
Sakamoto et al. [21] & 2003 & 22 & 11 & 38 \\
Thelen et al. [3] & 2008 & 26 & 9 & 31.5 \\
Tsujimoto et al. [4] & 2010 & 17 & 34 & \\
\hline
\end{tabular}


non-resected subgroup (see Fig. 1) was, at least in part, a result of more extended tumor growth within the liver in these patients, and this factor may have influenced the significance of the difference in survival data between the two groups.

Although, due to the small size of our study group, we did not find statistically significant factors within the group that could predict outcome (survival and tumor recurrence) we believe that such predictive factors may exist and could be detected in larger patient populations. All existing classifications of gastric cancer are based on clinical and histopathological findings, but they often fail to predict an individual prognosis. We believe that useful prognostic markers will be derived from molecular investigations in the future. As an example, we recently published preliminary data that suggested a strong correlation between the degree of chromosomal aberration and survival for intestinal-type gastric cancer [19].

There are very few data available in the literature on the outcome following radiofrequency ablation for hepatic metastasized gastric cancer [20]. Within our study group, there were 5 patients who underwent that procedure and they showed an overall 5-year survival rate of 53\%. Due to the less invasive approach and the repeatability of the procedure, radiofrequency ablation may become an alternative to hepatic resection, especially in cases of borderline resectability, as the procedure is successfully practised for other indications; however, studies of clinical outcomes in larger study groups are needed in the future.

In accordance with other studies [3,21] confined to surgical therapy of gastric liver metastases, there were few surgical complications and no peri-operative mortality in our study population. So far, we consider this procedure as being safe for patients who are carefully selected for surgery.

\section{Conclusion}

Based on the currently available data and on our analysis, we believe that liver resection for hepatic metastasized gastric cancer could, possibly, improve the clinical outcome and could be performed if extra-hepatic non-curable tumor dissemination can be ruled out. Moreover, even multiple liver tumors and a bilateral spread within the liver could be treated by surgical therapy in strictly selected cases as long as all tumors can be removed curatively.

\section{References}

1. Jemal A, Tiwari RC, Murray T, Ghafoor A, Samuels A, Ward E, et al. Cancer statistics, 2004. CA Cancer J Clin. 2004;54:8-29.
2. Shah MA, Kelsen DP. Gastric cancer: a primer on the epidemiology and biology of the disease and an overview of the medical management of advanced disease. J Natl Compr Canc Netw. 2010;8:437-47.

3. Thelen A, Jonas S, Benckert C, Lopez-Hanninen E, Neumann U, Rudolph B, et al. Liver resection for metastatic gastric cancer. Eur J Surg Oncol. 2008;34:1328-34.

4. Tsujimoto H, Ichikura T, Ono S, Sugasawa H, Hiraki S, Sakamoto $\mathrm{N}$, et al. Outcomes for patients following hepatic resection of metastatic tumors from gastric cancer. Hepatol Int. 2010;4:406-13.

5. Okano K, Maeba T, Ishimura K, Karasawa Y, Goda F, Wakabayashi $\mathrm{H}$, et al. Hepatic resection for metastatic tumors from gastric cancer. Ann Surg. 2002;235:86-91.

6. Ochiai T, Sasako M, Mizuno S, Kinoshita T, Takayama T, Kosuge $\mathrm{T}$, et al. Hepatic resection for metastatic tumours from gastric cancer: analysis of prognostic factors. $\mathrm{Br} \mathrm{J}$ Surg. 1994;81:1175-8.

7. Miyazaki M, Itoh H, Nakagawa K, Ambiru S, Shimizu H, Togawa A, et al. Hepatic resection of liver metastases from gastric carcinoma. Am J Gastroenterol. 1997;92:490-3.

8. Fujii K, Fujioka S, Kato K, Machiki Y, Kutsuna Y, Ishikawa A, et al. Resection of liver metastasis from gastric adenocarcinoma. Hepatogastroenterology. 2001;48:368-71.

9. Zacherl J, Zacherl M, Scheuba C, Steininger R, Wenzl E, Muhlbacher $\mathrm{F}$, et al. Analysis of hepatic resection of metastasis originating from gastric adenocarcinoma. J Gastrointest Surg. 2002;6:682-9.

10. Clavien PA, Barkun J, de Oliveira ML, Vauthey JN, Dindo D, Schulick RD, et al. The Clavien-Dindo classification of surgical complications: five-year experience. Ann Surg. 2009;250:187-96.

11. Manfredi S, Lepage C, Hatem C, Coatmeur O, Faivre J, Bouvier AM. Epidemiology and management of liver metastases from colorectal cancer. Ann Surg. 2006;244:254-9.

12. Shimada H, Tanaka K, Endou I, Ichikawa Y. Treatment for colorectal liver metastases: a review. Langenbecks Arch Surg. 2009;394:973-83.

13. D'Angelica M, Gonen M, Brennan MF, Turnbull AD, Bains M, Karpeh MS. Patterns of initial recurrence in completely resected gastric adenocarcinoma. Ann Surg. 2004;240:808-16.

14. Maehara Y, Moriguchi S, Kakeji Y, Kohnoe S, Korenaga D, Haraguchi $\mathrm{M}$, et al. Pertinent risk factors and gastric carcinoma with synchronous peritoneal dissemination or liver metastasis. Surgery. 1991;110:820-3.

15. Takada Y, Otsuka M, Seino K, Taniguchi H, Koike N, Kawamoto $\mathrm{T}$, et al. Hepatic resection for metastatic tumors from noncolorectal carcinoma. Hepatogastroenterology. 2001;48:83-6.

16. Harrison LE, Brennan MF, Newman E, Fortner JG, Picardo A, Blumgart LH, et al. Hepatic resection for noncolorectal, nonneuroendocrine metastases: a fifteen-year experience with ninetysix patients. Surgery. 1997;121:625-32.

17. Hemming AW, Sielaff TD, Gallinger S, Cattral MS, Taylor BR, Greig PD, et al. Hepatic resection of noncolorectal nonneuroendocrine metastases. Liver Transpl. 2000;6:97-101.

18. Kerkar SP, Kemp CD, Avital I. Liver resections in metastatic gastric cancer. HPB (Oxford). 2010;12:589-96.

19. Dittmar Y, Posorski N, Rauchfuss F, Voigt R, Heise M, Jandt K, et al. Relationship between degree of chromosomal aberration and survival in intestinal-type gastric cancer-a preliminary report based on three cases of hepatic metastasized gastric cancer with long-time survival. Onkologie. 2010;33:591-6.

20. An JY, Kim JY, Choi MG, Noh JH, Choi D, Sohn TS, et al. Radiofrequency ablation for hepatic metastasis from gastric adenocarcinoma. Yonsei Med J. 2008;49:1046-51.

21. Sakamoto Y, Ohyama S, Yamamoto J, Yamada K, Seki M, Ohta $\mathrm{K}$, et al. Surgical resection of liver metastases of gastric cancer: 
an analysis of a 17-year experience with 22 patients. Surgery. 2003;133:507-11.

22. Imamura H, Matsuyama Y, Shimada R, Kubota M, Nakayama A, Kobayashi A, et al. A study of factors influencing prognosis after resection of hepatic metastases from colorectal and gastric carcinoma. Am J Gastroenterol. 2001;96:3178-84.

23. Ambiru S, Miyazaki M, Ito $H$, Nakagawa $K$, Shimizu $H$, Yoshidome $\mathrm{H}$, et al. Benefits and limits of hepatic resection for gastric metastases. Am J Surg. 2001;181:279-83.
24. Saiura A, Umekita N, Inoue S, Maeshiro T, Miyamoto S, Matsui $\mathrm{Y}$, et al. Clinicopathological features and outcome of hepatic resection for liver metastasis from gastric cancer. Hepatogastroenterology. 2002;49:1062-5.

25. Shirabe K, Shimada M, Matsumata T, Higashi H, Yakeishi Y, Wakiyama SV, et al. Analysis of the prognostic factors for liver metastasis of gastric cancer after hepatic resection: a multiinstitutional study of the indications for resection. Hepatogastroenterology. 2003;50:1560-3. 